\title{
Microarray studies on effects of Pneumocystis carinii infection on global gene expression in alveolar macrophages
}

Bi-Hua Cheng ${ }^{1,2}$, Yunlong Liu ${ }^{3,4,5}$, Xiaoling Xuei, ${ }^{5,6}$, Chung-Ping Liao ${ }^{7}$, Debao Lu ${ }^{8}$, Mark E Lasbury ${ }^{7}$, Pamela J Durant ${ }^{7}$, Chao-Hung Lee Le, $^{7 *}$

\begin{abstract}
Background: Pneumocystis pneumonia is a common opportunistic disease in AIDS patients. The alveolar macrophage is an important effector cell in the clearance of Pneumocystis organisms by phagocytosis. However, both the number and phagocytic activity of alveolar macrophages are decreased in Pneumocystis infected hosts. To understand how Pneumocystis inactivates alveolar macrophages, Affymetrix GeneChip ${ }^{\circledast}$ RG-U34A DNA microarrays were used to study the difference in global gene expression in alveolar macrophages from uninfected and Pneumocystis carinii-infected Sprague-Dawley rats.

Results: Analyses of genes that were affected by Pneumocystis infection showed that many functions in the cells were affected. Antigen presentation, cell-mediated immune response, humoral immune response, and inflammatory response were most severely affected, followed by cellular movement, immune cell trafficking, immunological disease, cell-to-cell signaling and interaction, cell death, organ injury and abnormality, cell signaling, infectious disease, small molecular biochemistry, antimicrobial response, and free radical scavenging. Since rats must be immunosuppressed in order to develop Pneumocystis infection, alveolar macrophages from four rats of the same sex and age that were treated with dexamethasone for the entire eight weeks of the study period were also examined. With a filter of false-discovery rate less than 0.1 and fold change greater than 1.5, 200 genes were found to be up-regulated, and 144 genes were down-regulated by dexamethasone treatment. During Pneumocystis pneumonia, 115 genes were found to be up- and 137 were down-regulated with the same filtering criteria. The top ten genes up-regulated by Pneumocystis infection were Cxcl10, Spp1, S100A9, Rsad2, S100A8, Nos2, RT1-Bb, Lcn2, RT1-Db1, and Srgn with fold changes ranging between 12.33 and 5.34; and the top ten down-regulated ones were Lgals1, Psat1, Tbc1d23, Gsta1, Car5b, Xrcc5, Pdlim1, Alcam, Cidea, and Pkib with fold changes ranging between -4.24 and -2.25 .

Conclusions: In order to survive in the host, Pneumocystis organisms change the expression profile of alveolar macrophages. Results of this study revealed that Pneumocystis infection affects many cellular functions leading to reduced number and activity of alveolar macrophages during Pneumocystis pneumonia.
\end{abstract}

\footnotetext{
* Correspondence: chlee@iupui.edu

${ }^{7}$ Department of Pathology and Laboratory Medicine, Indiana University

School of Medicine, Indianapolis, IN 46202, USA
} 


\section{Background}

Pneumocystis pneumonia (PCP) is the most common opportunistic disease in AIDS patients [1,2]. During the early stage of the AIDS epidemic, PCP occurred in 60-80\% of HIV infected patients in the United States and Western Europe [3]. Characteristic pathology features of PCP include infiltration of inflammatory cells in the lung, thickened alveolar septa, and foamy exudates in the alveoli.

Since Pneumocystis has a typical morphology of protozoa, it was initially considered as protozoa. It is now classified as a fungus because the composition and structure of its cell wall $[4,5]$ and nucleotide sequences are more similar to those of fungi than to those of protozoa [6-9]. Although Pneumocystis organisms are found in many different species of mammals, they are strictly species specific [10]. Therefore, Pneumocystis from different host species has different names [11]. Among the more common ones, human Pneumocystis is called Pneumocystis jirovecii. Rat Pneumocystis is referred to as $P$. carinii; another rat Pneumocystis strain is called P. wakefieldii. Mouse Pneumocystis is named P. murina.

In immunocompetent humans and animals, alveolar macrophages (AMs) protect the hosts against Pneumocystis infection by actively removing this extracellular organism from the alveoli. However, AMs from Pneumocystis-infected animals are defective in phagocytosis $[12,13]$, and the number of AMs in humans and animals with PCP is reduced [14-16]. These two defects impair the innate immunity against Pneumocystis infection. The reduction in alveolar macrophage (AM) number is mainly due to increased rate of apoptosis [17]. A recent study demonstrates that increased levels of intracellular polyamines trigger this apoptosis [18].

The increase in polyamine levels in AMs is due to increased de novo synthesis and uptake of exogenous polyamines [19]. Very little is known about the defect in phagocytosis during PCP. Decreased expression of macrophage receptors such as mannose receptor is a possible cause [20]. In this study, we used DNA microarrays to study global gene expression in AMs from $P$. carinii-infected rats to better understand the mechanisms of pathogenesis of PCP.

\section{Methods \\ Rat PCP Model}

$P$. carinii infection in rats was established as described previously [21]. Briefly, female Sprague-Dawley rats (Harlan, Indianapolis, IN) of 120-140 g were divided into three groups designated Normal, Dex, and Dex-Pc rats. Normal rats were immunocompetent and uninfected. Since rats must be immunosuppressed in order to develop PCP upon inoculation of Pneumocystis organisms, they were immunosuppressed by giving dexamethasone $(1.8 \mathrm{mg} /$ liter $)$ continuously in drinking water to reduce the number of CD4+ T lymphocytes. These rats were referred to as Dex rats. Although the Dex rats were continuously immunosuppressed for nine weeks, they showed no signs of disease. Dex-Pc rats were Dex rats transtracheally inoculated with $7.5 \times 10^{6}$ $P$. carinii organisms one week after initiation of immunosuppression. To prevent other opportunistic infections, immunosuppressed rats were given 10,000 units of penicillin (Butler, Dublin, $\mathrm{OH}$ ) weekly by intramuscular (i.m.) injection. All P. carinii-infected rats showed signs of PCP including weight loss, dark eyes, hunched posture, and respiratory distress eight weeks after inoculation of the organisms and were sacrificed for isolation of AMs. Age-matched Normal rats were used as controls, while age-matched Dex rats were used to control for effect of the steroid treatment. Giemsa and silver staining of lung impression smears was performed to determine the existence of Pneumocystis and other microorganisms. Any lungs that contained other microorganisms were excluded. All animal studies were approved by the Indiana University Animal Care and Use Committee and supervised by veterinarians.

\section{Isolation of alveolar macrophages}

Rats were anesthetized by i.m. injection of $0.1 \mathrm{ml}$ ketamine mixture $(80 \mathrm{mg} / \mathrm{ml}$ ketamine hydrochloride, 0.38 $\mathrm{mg} / \mathrm{ml}$ atropine, and $1.76 \mathrm{mg} / \mathrm{ml}$ acepromazine) and then sacrificed. The thoracic cavity and trachea were exposed by dissection. Bronchoalveolar lavage fluid (BALF) was obtained by instilling $5 \mathrm{ml}$ of sterile phosphate buffered saline (PBS) one at a time into rat lungs with a 14-gauge angiocath (BD Biosciences, Bedford, MA) and then recovered until a total of $50 \mathrm{ml}$ BALF was obtained [22]. The cells in this 50 -ml BALF were pelleted by centrifugation at $300 \times g$ for $10 \mathrm{~min}$ and then resuspended in $5 \mathrm{ml}$ of Dulbecco's Modified Eagle Medium (DMEM). AMs were isolated by adherence on plastic tissue culture dishes at $37^{\circ} \mathrm{C}$ with $5 \% \mathrm{CO}_{2}$ for $1 \mathrm{hr}$ followed by washing with warm PBS three times to remove unattached cells. The purity of AMs was greater than $97 \%$ as determined by anti-RMA staining described previously [23].

\section{Isolation of RNA from alveolar macrophages}

AMs from four each of Normal, Dex, and Dex-Pc rats were used. Total RNA was isolated individually from each sample using the RNeasy kit (Qiagen) according to manufacturer's instructions. Approximately $2 \times 10^{6}$ cells from each animal were used. The cells were washed with PBS and then lysed with $350 \mu \mathrm{l}$ of Buffer RLT in the kit. The cell lysate was passed five times through a 20 gauge needle and then through the Genomic DNA Eliminator spin column by centrifugation, followed by addition of $350 \mu \mathrm{l}$ of $70 \%$ ethanol to the flow through. The mixture was transferred to an RNeasy spin column 
placed in a $2 \mathrm{ml}$ collection tube. The flow-through was discarded after a $15 \mathrm{~s}$ centrifugation at $8000 \times g$. The column was washed with $700 \mu$ l of Buffer RW1 and then with $500 \mu$ of Buffer RPE twice. Total RNA was eluted from the column with $30 \mu \mathrm{l}$ of RNase-free water and quantified by spectrophotometer.

\section{Microarray analysis}

The Affymetrix GeneChip RG-U34A, containing 8799 rat genes and EST sequences, was used for the microarray analysis. Briefly, $2.5 \mu \mathrm{g}$ of total RNA from each rat was reversely transcribed, using the standard 3'IVT protocol as described previously [24], and hybridized to a GeneChip. A total of 12 GeneChips were used, four for each sample group from Normal, Dex, and Dex-Pc rats. The data were first analyzed with Microarray Suite version 5.0 (MAS 5.0) using Affymetrix default analysis settings and global scaling as normalization method. The trimmed mean target intensity of each array was arbitrarily set to 1000 . Comparisons of global gene expression and identification of genes that were up- or down-regulated by dexamethasone treatment or by $P$. carinii infection in AMs from the three different groups of rats (Normal, Dex, and Dex-Pc) were performed with the Partek Genomic Suite 6.4 Software (Partek Inc., St. Louis, MO). Identification of cellular functions affected by dexamethasone or Pneumocystis infection was achieved by using the Ingenuity Pathway Analysis (IPA) software (Ingenuity Systems Inc. Redwood City, CA). The microarray data generated in this study have been deposited in the Gene Expression Omnibus with the accession number GSE20149.

\section{Real-time RT-PCR}

Approximately $0.2 \mu \mathrm{g}$ of each total AM RNA sample was reversely transcribed to cDNA using the iScript cDNA synthesis kit (Bio-Rad, Hercules, CA) and random primers in a total reaction volume of $20 \mu \mathrm{l}$. The reaction mixtures were incubated at $25^{\circ} \mathrm{C}$ for $5 \mathrm{~min}, 42^{\circ}$ $\mathrm{C}$ for $30 \mathrm{~min}$, and $85^{\circ} \mathrm{C}$ for $5 \mathrm{~min}$. Of this, $2 \mu \mathrm{l}$ of each cDNA product was used for quantitative PCR analysis. Real-time RT-PCRs for various target genes were performed using the Assays-on-Demand ${ }^{\mathrm{mm}}$ gene expression kits. Each kit contained two unlabeled PCR primers and a FAM ${ }^{\mathrm{Tm}}$-labeled TaqMan probe (Applied Biosystems, Foster City, CA). Since the expression of the ribosomal protein S8 (RPS8) is not affected by Pneumocystis infection, RPS8 mRNAs were assayed in an identical manner as an internal control as described previously [25].

\section{Results}

\section{Quality of microarray data}

Since each GeneChip contained 8799 probe sets, a total of 105,588 expression data points were generated from the twelve arrays. Principle component analysis (PCA) was first performed to examine the correlations among the data produced from different arrays. The results of the first three principal components, which included the variance of $83.5 \%$ of the expression data points of each sample, are shown in Fig. 1. Each blue, red, or green dot represents the overall expression pattern of each AM sample from Normal, Dex, or Dex-Pc rats, respectively (Fig. 1). The PCA analysis showed that the samples within each rat group were closely clustered together, whereas the samples between rat groups were distinctly separated, indicating that the quality of the microarray data was excellent. The PCA results also indicated that the global expression patterns in AMs of the same rat group were similar, whereas those in AMs of different rat groups were different.

\section{Hierarchical clustering analysis of differentially expressed genes}

After ANOVA, 3473 genes were found to be differentially expressed due to dexamethasone treatment or Pneumocystis infection and were analyzed by hierarchical clustering using the Partek software (Fig. 2). Genes that were differentially expressed due to Pneumocystis infection were divided into four categories. The first one includes genes whose expressions were not affected by Pneumocystis infection. The second category includes those that were expressed at low levels but were up regulated by Pneumocystis infection. The third category contains genes that were expressed at high levels and were not affected by Pneumocystis infection. The fourth category includes those that were expressed at high levels but were down regulated by Pneumocystis infection. The same four categories of gene expressions in AMs from dexamethasone treated rats were observed.

\section{Functional pathways affected by dexamethasone or Pneumocystis infection}

To ensure the accuracy of the results, only the differentially expressed genes with a false-discovery rate (FDR) $\leq 0.1$ and a fold change (FC) $\geq 1.5$ were further analyzed. With IPA, the following functions were found to be significantly affected by dexamethasone (listed in the order of significance from highest to lowest): cell death, small molecular biochemistry, immunological disease, cellular movement, cell-to-cell signaling and interaction, immune cell trafficking, antigen presentation, cellmediated immune response, humoral immune response, inflammatory response, respiratory disease, cell signaling, infectious disease, organ injury and abnormality, and free radical scavenging. These functions were also affected by Pneumocystis infection, but in a different order of significance (also listed in the order of significance from highest to lowest): antigen presentation, cell- 


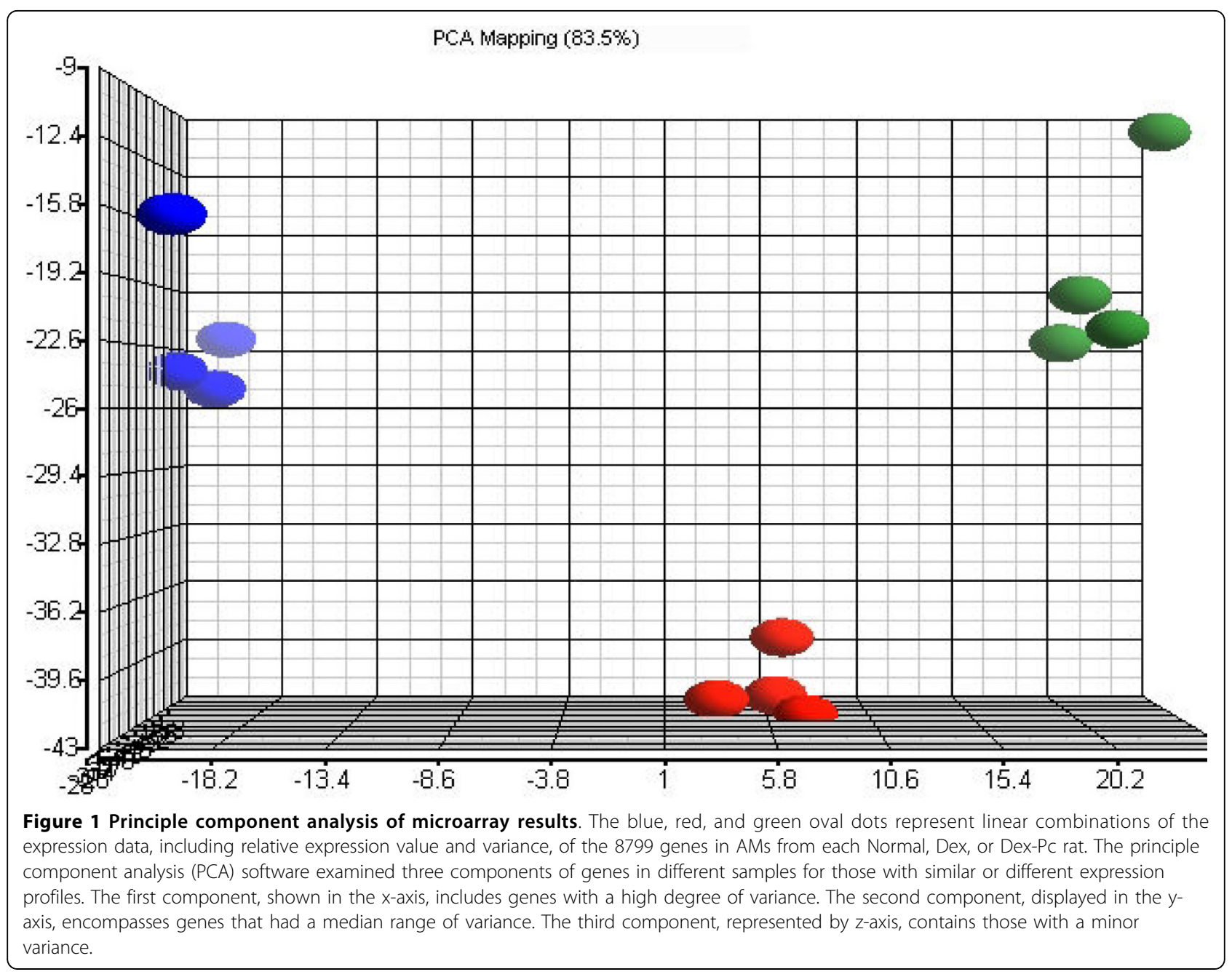

mediated immune response, humoral immune response, and inflammatory response were equally and most severely affected, followed by cellular movement, immune cell trafficking, immunological disease, cell-tocell signaling and interaction, cell death, organ injury and abnormality, cell signaling, infectious disease, small molecular biochemistry, antimicrobial response, and free radical scavenging (Fig. 3).

The functions that were affected by Pneumocystis infection were further classified into four major groups: immune response, inflammation, cell death, and phagocytosis (Fig. 4). The immune response group included cellmediated immune response, humoral immune response, and antigen presentation. The cell death group included cell death and organ injury and abnormality; while cell signaling, cell-to-cell interaction, cell movement, antimicrobial response, immune cell trafficking, and free radical scavenging were included in the phagocytosis group. Genes that were differentially expressed due to Pneumocystis infection not dexamethasone treatment in each group are shown in Table 1. It is interesting to note that these four functions share many of the same genes. Among these, Lgals1, Alcam, and Cd55 genes were down regulated; while Sod2, Soc3, Prf1, Il10, Mmp7, Sell, Psmb9, Oas1a, Clu, Ccr1, Mx1, Il8rb, Ccr5, Ccl5, Irf7, Nos2, and Cxcl10 genes were up regulated in all four functional groups. Cat and Hip1 genes that belong to both the cell death and phagocytosis groups were down regulated. In the cell death group, Hdac2, Bnip3L, Nr1h3, and Ppp6C genes were down regulated, and the Tap2 gene was up regulated. Mmp14 and Mmp8 in all but the immune response group, $\mathrm{Mx} 2$ in both immune response and phagocytosis groups, Gbp2 in both immune response and inflammation groups, and Tap1 in the immune response group were up-regulated.

Among the genes that were affected by dexamethasone and further affected by Pneumocystis infection, Mgst1 and Hspa1b genes were down-regulated, while Cd14, Irf8, Il1b, Cxcl13, Cxcr4, Fn1, Irf1, Cd74, S100a9, and Spp1 genes were up-regulated in all four groups 


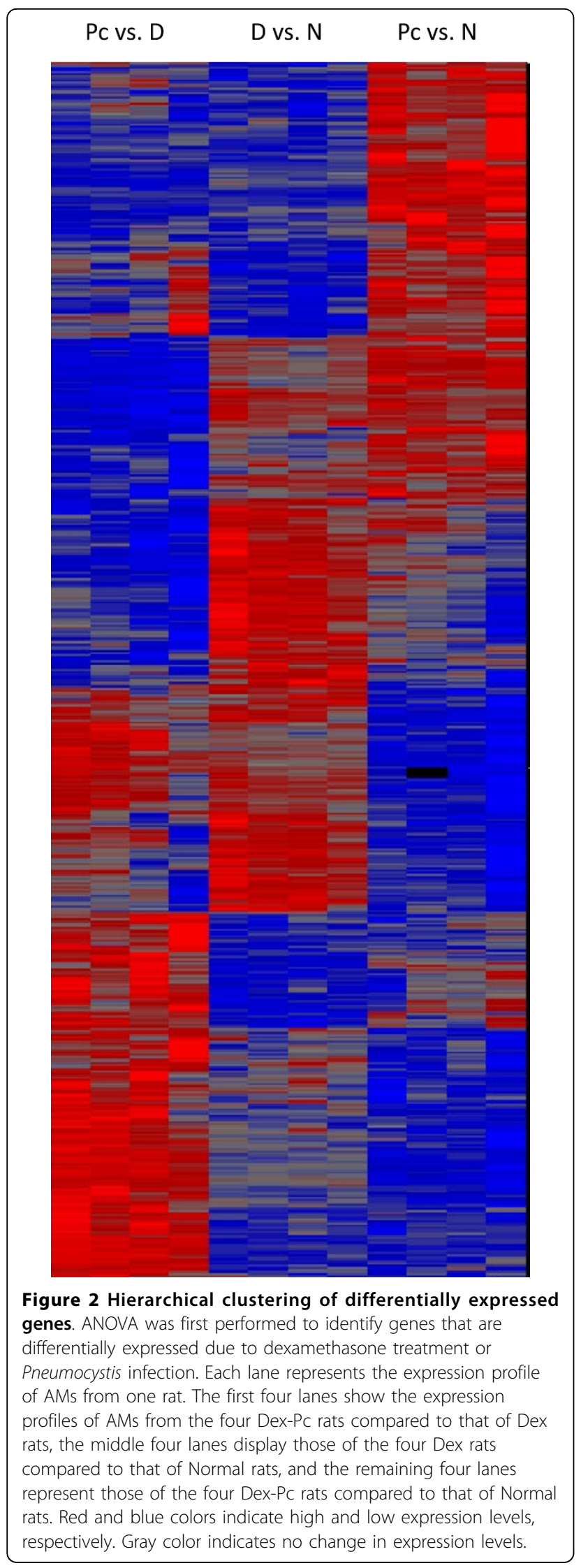

(Table 2). The following genes were also up-regulated in some groups: Pld1 and Xdh in both cell death and phagocytosis; C1qb in both immune response and inflammation groups; Alox 5 in all but the inflammation group; and Srgn in both immune response and cell death groups. Genes that were down-regulated in some groups include: Gnptg, Fah, Bloc1s2, and Prkacb in the cell death group; Dnaja1 in both cell death and phagocytosis groups; Tfp1 in all but the cell death group; Alox 5 in all but the inflammation group; and Mmp12 in all but the immune response group.

\section{Subcellular locations of differentially expressed genes}

Among the proteins encoded by the genes whose expressions were affected by both dexamethasone and Pneumocystis in the four functional groups, IL1B, IL10, SRGN, MMP12, SPP1, and C1QB are secreted. CD74, CXCR4, SIRPA, FN1, and CD14 are membrane proteins, while MGST1, XDH, PLD1, S100A9, GNPTG, PTPN6, ALOX5, FAH, PLDN, and PRKACB proteins are located in the cytoplasm. IRF1, IRF8, DNAJA1, and NR0B2 are nuclear proteins (Fig. 5). Both IL-1B and IL-10 have a direct relationship with IRF1 and may affect its expression. IL-10 has an indirect relationship with IRF8, and IRF8 can regulate the expression of IL-1B. Except for Mgst1, Alox5, Fah, Pldn, Prkacb, Dnaja1, and Nrob2, all other genes are shown to have direct or indirect relationships between each other. This analysis also revealed four key proteins including IL-1B, IL-10, IRF1, and IRF8 that are central to the regulation of the differentially expressed genes in the four functional groups mentioned above.

\section{Effect of dexamethasone on AM gene expression ( $\mathrm{N}$ vs. $\mathrm{D})$}

When AM gene expression profiles between Normal and Dex (N. vs. D) groups were compared, 200 genes were found to be up-regulated and 144 genes were found to be down-regulated by dexamethasone treatment with an FDR $\leq 0.1$ and $\mathrm{FC} \geq 1.5$ (Additional file 1, Tables S1 and S2). The top ten up-regulated genes were Cxcl2 (13.43), Fn1 (10.19), Ccl2 (9.99), Cd81 (9.07), Il1b (8.65), Trf (8.55), Slc28a2 (8.24), Cd14 (8.10), Cdh17 (7.15), and Sdc4 (6.52); and the top ten down-regulated ones were Hspa1a (-17.44), Hspa1b (-13.90), Hspb1 (-7.76), Hsph1 (-6.70), Tac1 (-6.16), Prkcb (-5.68), Atf3 (-4.91), Dnajb1 (-4.88), Fos (-4.54), and Ptprc (-3.92). Values in the parentheses are fold changes.

\section{Effect of Pneumocystis infection on alveolar}

\section{macrophage gene expression (Pc vs. D)}

Comparison of the expression profiles between Dex-Pc and Dex groups (Pc vs. D) revealed 116 genes up-regulated and 140 genes down-regulated by Pneumocystis 


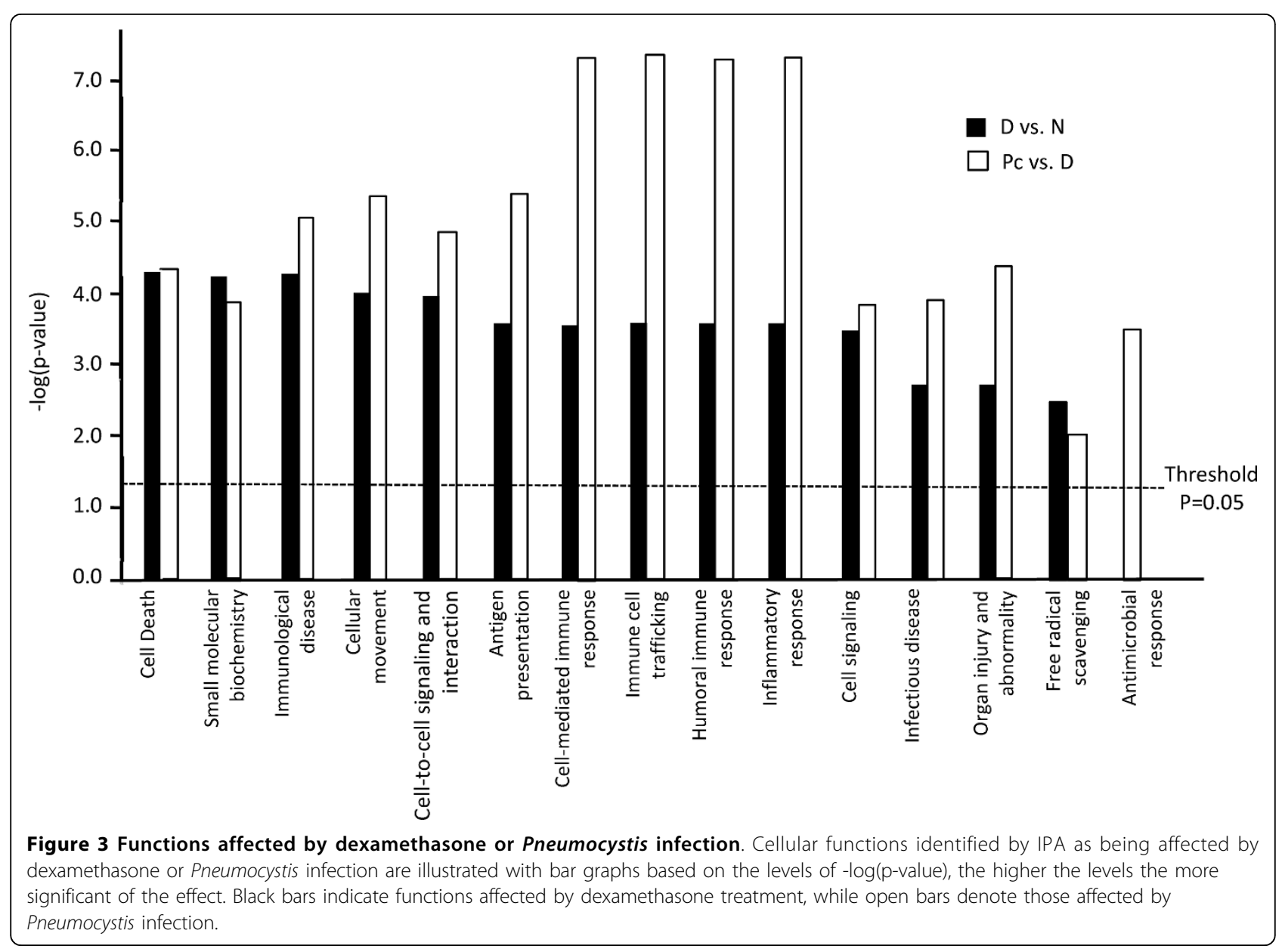

infection (Additional file 1, Tables S3 and S4) also with the filter of FDR $\leq 0.1$ and $F C \geq 1.5$. The top ten upregulated genes were Cxcl10 (12.33), Spp1 (11.78), S100A9 (11.55), Rsad2 (7.62), S100A8 (6.52), Nos2 (6.35), RT1-Bb (5.42), Lcn2 (5.36), RT1-Db1 (5.35), and Srgn (5.34); and the top ten down-regulated ones were Lgals1 (-4.24), Psat1 (-3.10), Tbc1d23 (-3.00), Gsta1 (-2.63), Car5b (-2.47), Xrcc5 (-2.35), Pdlim1 (-2.33), Alcam (-2.29), Cidea (-2.27), and Pkib (-2.25).

\section{Genes affected by dexamethasone but reversed by Pneumocystis infection}

Since both dexamethasone and $P$. carinii infection have effects on gene expression in AMs, genes that were affected differently were examined. Thirty-two genes that were up regulated by dexamethasone treatment were reversely down regulated by Pneumocystis infection (Table 3). Another 32 genes that were up-regulated by dexamethasone were further up-regulated by Pneumocystis infection (Table 4). Nine genes that were down regulated by dexamethasone were found to be up regulated by Pneumocystis infection (Table 5), and twenty- one genes that were down-regulated by dexamethasone were further down-regulated by Pneumocystis infection (Table 6).

\section{Confirmation of microarray results by RT-PCR}

To ensure that the expression levels of genes determined by the microarrays were correct, real-time RTPCR was performed on several selected target genes. Results confirmed that Cat was down-regulated and Cxcl10, Lcn2, Nos2, Sdc1, and Spp1 were up-regulated (Table 7). Genes whose expression levels were not significantly changed during PCP include Odc1, Smo, and RPS8.

\section{Discussion}

In this study, DNA microarrays were used to study effects of $P$. carinii infection on global gene expression in AMs from rats. Since rats were immunosuppressed with dexamethasone in order to establish Pneumocystis infection, gene expression affected by dexamethasone treatment was also investigated. A total of 1682 genes in AMs were found to be affected by dexamethasone, and 


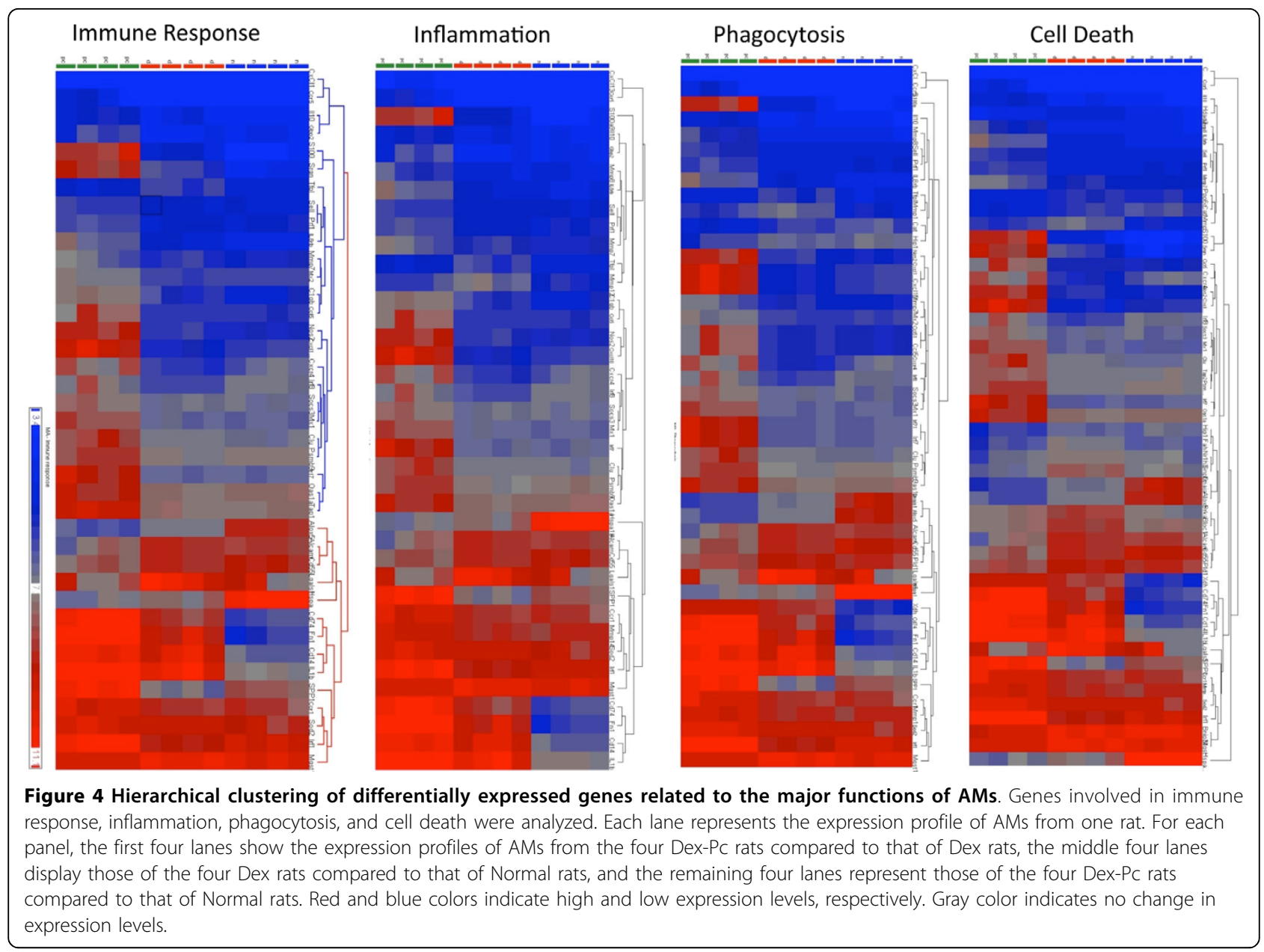

1705 genes were found to be affected by Pneumocystis infection with an FDR of $\leq 0.1$. With a more stringent filtering criteria of FDR $\leq 0.1$ and $F C \geq 1.5,200$ genes were found to be up regulated and 144 genes down regulated by dexamethasone, and 115 genes were up regulated and 137 genes down regulated by Pneumocystis infection. Principle component analyses revealed that the results generated from the twelve microarrays were of excellent quality (Fig. 1). Because of costs, only one time point (eight weeks after organism inoculation) was examined in this study; this was a time when the DexPc animals were heavily infected with the organism.

An in vitro microarray study had been conducted previously using the human A549 alveolar epithelial cells line [26]. The cells were incubated with $P$. carinii organisms for $2 \mathrm{hr}$ and then analyzed for global gene expression with the Affymetrix human U95 Arrays. The results showed that some epithelial genes controlling cell cycle progression such as the ras-related rho gene and cyclin G-interacting protein gene were highly upregulated by $P$. carinii. TNF-inducible protein and the pim oncogene that are involved in apoptosis signaling as well as inflammatory cytokines and chemokines including Gro-beta, IL-8, ICAM-1, MIP-3 and RANTES were also up-regulated [26]. Another microarray study was conducted by Hernandez-Novoa et al. [27]. They used total RNA from lung cells of wild type and CD40L knockout C57BL/6 mice infected with $P$. murina for various length of time (7 to 41 days) and found that 349 genes related to immune responses were up-regulated in wild type mice but not in CD40L-KO mice. The genes involved in innate response were up-regulated first followed by those involved in adaptive immunity. This study revealed how healthy, immunocompetent hosts respond to Pneumocystis infection [27]. In our study, we used AMs from $P$. carinii-infected rats to investigate how Pneumocystis affects AM functions by identifying genes that are up- or down-regulated during Pneumocystis infection.

IPA analyses showed that many cellular functions of AMs were affected by Pneumocystis infection (Fig. 3). Among them, antigen presentation, cell-mediated immune response, humoral immune response and inflammatory response were most profoundly affected. 
Table 1 Genes involved in the four major AM functions affected by Pneumocystis infection

\begin{tabular}{|c|c|c|c|c|c|}
\hline Gene & Pc vs. D & Immune Response (23 genes) & Inflammation ( 23 genes) & Cell Death (29 genes) & Phagocytosis (25 genes) \\
\hline Lgals1 & -4.24 & $\downarrow$ & $\downarrow$ & $\downarrow$ & $\downarrow$ \\
\hline Alcam & -2.29 & $\downarrow$ & $\downarrow$ & $\downarrow$ & $\downarrow$ \\
\hline Cd55 & -1.68 & $\downarrow$ & $\downarrow$ & $\downarrow$ & $\downarrow$ \\
\hline Cat & -1.64 & NA & NA & $\downarrow$ & $\downarrow$ \\
\hline Hip1 & -1.63 & NA & NA & $\downarrow$ & $\downarrow$ \\
\hline $\mathrm{Hdac} 2$ & -1.61 & NA & NA & $\downarrow$ & NA \\
\hline Bnip31 & -1.58 & NA & NA & $\downarrow$ & NA \\
\hline Nr1h3 & -1.52 & NA & NA & $\downarrow$ & NA \\
\hline Ppp6c & -1.52 & NA & NA & $\downarrow$ & NA \\
\hline Sod2 & 1.50 & $\uparrow$ & $\uparrow$ & $\uparrow$ & $\uparrow$ \\
\hline Socs3 & 1.67 & $\uparrow$ & $\uparrow$ & $\uparrow$ & $\uparrow$ \\
\hline Tap2 & 1.67 & NA & NA & $\uparrow$ & NA \\
\hline Mmp14 & 1.78 & NA & $\uparrow$ & $\uparrow$ & $\uparrow$ \\
\hline Prf1 & 1.78 & $\uparrow$ & $\uparrow$ & $\uparrow$ & $\uparrow$ \\
\hline ॥10 & 1.87 & $\uparrow$ & $\uparrow$ & $\uparrow$ & $\uparrow$ \\
\hline Mmp7 & 1.92 & $\uparrow$ & $\uparrow$ & $\uparrow$ & $\uparrow$ \\
\hline$M \times 2$ & 1.94 & $\uparrow$ & NA & NA & $\uparrow$ \\
\hline Sell & 1.97 & $\uparrow$ & $\uparrow$ & $\uparrow$ & $\uparrow$ \\
\hline Psmb9 & 2.14 & $\uparrow$ & $\uparrow$ & $\uparrow$ & $\uparrow$ \\
\hline Oas1a & 2.32 & $\uparrow$ & $\uparrow$ & $\uparrow$ & $\uparrow$ \\
\hline Mmp8 & 2.34 & NA & $\uparrow$ & $\uparrow$ & $\uparrow$ \\
\hline Clu & 2.37 & $\uparrow$ & $\uparrow$ & $\uparrow$ & $\uparrow$ \\
\hline Ccr1 & 2.40 & $\uparrow$ & $\uparrow$ & $\uparrow$ & $\uparrow$ \\
\hline Mx1 & 2.42 & $\uparrow$ & $\uparrow$ & $\uparrow$ & $\uparrow$ \\
\hline$\| 8 r b$ & 2.78 & $\uparrow$ & $\uparrow$ & $\uparrow$ & $\uparrow$ \\
\hline Ccr5 & 2.79 & $\uparrow$ & $\uparrow$ & $\uparrow$ & $\uparrow$ \\
\hline Gbp2 & 3.21 & $\uparrow$ & $\uparrow$ & NA & NA \\
\hline Tap1 & 3.47 & $\uparrow$ & NA & NA & NA \\
\hline Ccl5 & 3.58 & $\uparrow$ & $\uparrow$ & $\uparrow$ & $\uparrow$ \\
\hline Irf7 & 4.92 & $\uparrow$ & $\uparrow$ & $\uparrow$ & $\uparrow$ \\
\hline Nos2 & 6.35 & $\uparrow$ & $\uparrow$ & $\uparrow$ & $\uparrow$ \\
\hline Cxcl10 & 12.33 & $\uparrow$ & $\uparrow$ & $\uparrow$ & $\uparrow$ \\
\hline
\end{tabular}

Values shown are fold changes. Pc vs. D: expression affected by Pneumocystis (Pc) infection compared to the Dex (D) control. Up arrow ( $\uparrow$ ): up regulated by Pneumocystis infection; down arrow $(\downarrow)$ : down regulated by Pneumocystis infection; NA: not applicable to the function.

Up-regulation of genes involved in antigen presentation, such as Tap1, RT1-Bb and RT1-Db1, reflects the attempts AMs make to activate the adaptive immune responses. The observation that most genes involved in both cell-mediated and inflammatory responses were up regulated (Tables 1 and 2) implies that antigen presentation by AMs is functional during PCP. This postulation is consistent with that of Hernandez-Novoa et al. [27]. The fact that PCP progresses despite activation of cellmediated immune response and inflammatory response indicates that other cellular functions are disabled. Due to the lack of appropriate antibodies, immunosuppression of rats is usually achieved by treatment with dexamethasone which is known to have an antiinflammatory and a wide range of side effects. Results of this study revealed that in addition to the 1682 genes mentioned above, functions related to cell death, small molecule biochemistry (e.g., production of nitric oxide and reactive oxygen species), and immunological disease were most severely affected by dexamethasone (Fig. 3).

Dexamethasone and Pneumocystis infection were found to have opposite effects on certain genes. Of the 32 genes that were up-regulated by dexamethasone but down-regulated by Pneumocystis infection (Table 3), cadherin 17 (Cdh17) and glutathione-S-transferase alpha type2 (Gsta2) genes were most profoundly affected. Dexamethasone treatment increased Cdh17 expression by 7.15 fold, but Pneumocystis infection not only reversed this effect but also decreased its expression by 1.61 fold. Similarly, dexamethasone up-regulated Gsta2 by 4.77 fold, but Pneumocystis infection decreased it by 2.63 fold. Cadherin (calcium dependent adhesion molecule) 
Table 2 Genes involved in the four major AM functions affected by both dexamethasone and Pneumocystis infection

\begin{tabular}{|c|c|c|c|c|c|c|}
\hline Gene & Pc vs. D & D. vs. $\mathrm{N}$ & Immune Response (16 genes) & Inflammation (15 genes) & Cell Death ( 22 genes) & Phagocytosis (18 genes) \\
\hline Gnptg & -1.95 & 1.76 & NA & NA & $\downarrow$ & NA \\
\hline Fah & -1.80 & 1.50 & NA & NA & $\downarrow$ & NA \\
\hline Mmp12 & -1.70 & 2.50 & NA & $\downarrow$ & $\downarrow$ & $\downarrow$ \\
\hline Dnaja1 & -1.67 & -3.20 & NA & NA & $\downarrow$ & $\downarrow$ \\
\hline Tfp1 & -1.65 & 1.98 & $\downarrow$ & $\downarrow$ & NA & $\downarrow$ \\
\hline Bloc1s2 & -1.63 & 1.61 & NA & NA & $\downarrow$ & NA \\
\hline Prkacb & -1.56 & 2.03 & NA & NA & $\downarrow$ & NA \\
\hline Alox5 & -1.53 & -3.07 & $\downarrow$ & NA & $\downarrow$ & $\downarrow$ \\
\hline Mgst1 & -1.53 & 1.33 & $\downarrow$ & $\downarrow$ & $\downarrow$ & $\downarrow$ \\
\hline Hspa1b & -1.13 & -13.90 & $\downarrow$ & $\downarrow$ & $\downarrow$ & $\downarrow$ \\
\hline Pld1 & 1.076 & -1.05 & NA & NA & $\uparrow$ & $\uparrow$ \\
\hline$X d h$ & 1.74 & 5.55 & NA & NA & $\uparrow$ & $\uparrow$ \\
\hline $\mathrm{Cd} 14$ & 1.85 & 8.10 & $\uparrow$ & $\uparrow$ & $\uparrow$ & $\uparrow$ \\
\hline Irf8 & 2.13 & -1.61 & $\uparrow$ & $\uparrow$ & $\uparrow$ & $\uparrow$ \\
\hline$\| 1 b$ & 2.26 & 8.65 & $\uparrow$ & $\uparrow$ & $\uparrow$ & $\uparrow$ \\
\hline Cxcl13 & 2.41 & 4.17 & $\uparrow$ & $\uparrow$ & $\uparrow$ & $\uparrow$ \\
\hline Clqb & 2.64 & 2.04 & $\uparrow$ & $\uparrow$ & NA & NA \\
\hline Cxcr4 & 3.60 & -1.78 & $\uparrow$ & $\uparrow$ & $\uparrow$ & $\uparrow$ \\
\hline Fn1 & 4.20 & 10.19 & $\uparrow$ & $\uparrow$ & $\uparrow$ & $\uparrow$ \\
\hline Irf1 & 4.45 & -1.52 & $\uparrow$ & $\uparrow$ & $\uparrow$ & $\uparrow$ \\
\hline $\mathrm{Cd} 74$ & 4.95 & 4.50 & $\uparrow$ & $\uparrow$ & $\uparrow$ & $\uparrow$ \\
\hline Srgn & 5.34 & 3.39 & $\uparrow$ & NA & $\uparrow$ & NA \\
\hline S100a9 & 11.55 & 2.65 & $\uparrow$ & $\uparrow$ & $\uparrow$ & $\uparrow$ \\
\hline Spp1 & 11.78 & -1.72 & $\uparrow$ & $\uparrow$ & $\uparrow$ & $\uparrow$ \\
\hline
\end{tabular}

Values shown are fold changes. D vs. N: expression affected by dexathamethasone (D) treatment compared to the normal control (N); Pc vs. D: expression affected by Pneumocystis (Pc) infection compared to the Dex (D) control. Up arrow ( $\uparrow$ ): up regulated by Pneumocystis infection; down arrow ( $\downarrow$ ): down regulated by Pneumocystis infection; NA: not applicable to the function.

plays a very important role in cell adhesion and assembly of the actin cytoskeleton [28]. Actin filaments are linked to $\alpha$-catenin and to the cell membrane through vinculin which is linked to E-cadherin [29]. The decrease in cadherin expression during PCP may be a reason why AMs are defective in phagocytosis, as this function requires the actin cytoskeleton. Glutathione S-transferases (GSTs) link reduced glutathione via a sulfhydryl group to electrophilic centers on a variety of substrates [30]. This activity detoxifies compounds such as peroxidized lipids [31] that are generated during oxidative stress. The reduction in GST expression during PCP may explain the reduction in AM number as a decrease in GST expression would increase the concentration of toxic molecules such as reactive oxygen species [32] which can trigger apoptosis of AMs [33].

Equally important are genes that were down-regulated by dexamethasone but up-regulated by Pneumocystis infection. Among these genes (Spp1, Irf1, Cxcr4, Crp, Il1rn, Irf8, RT1-Aw2, Ier3, and Ccnl1) (Table 5), the secreted phosphoprotein 1 (Spp1) gene has the most dramatic reversal by Pneumocystic infection followed by interferon regulatory factor 1 (Irf1). The SPP1 protein is also known as bone sialoprotein, early T-lymphocyte activation (ETA-1), and most commonly osteopontin (Opn). Opn is one of the most abundantly expressed proteins in various lung diseases; it mediates diverse cellular functions such as adhesion, migration, and survival of several cell types including macrophages, $\mathrm{T}$ cells and dentritic cells $[34,35]$. OPN also functions as a Th1 cytokine, promotes cell-mediated immune responses, and plays a role in chronic inflammatory and autoimmune diseases and activation of immune cells [34]. Opn can be cleaved by thrombin to expose the sequence SVVYGLR which is a ligand of integrin receptors $\alpha 4 \beta 1$, $\alpha 9 \beta 1$, and $\alpha 9 \beta 4$ that are present on monocytes, macrophages, neutrophils, $\mathrm{T}$ cells, and mast cells [36,37]. Upregulation of Opn during Pneumocystis infection may reflect the action of AMs in an attempt to activate both innate and adaptive immunities through the integrin receptors. Opn expression has been found to be upregulated in AMs from smokers [38] and in titanium dioxide-induced lung disease in rats [39]; it is considered as a biomarker for particle-induced lung disease [39].

Both Irf- 1 and Irf- 8 genes were down-regulated by dexamethasone $(-1.52$ and -1.61 , respectively) but up regulated by Pneumocystis infection (4.45 and 2.13 fold, 


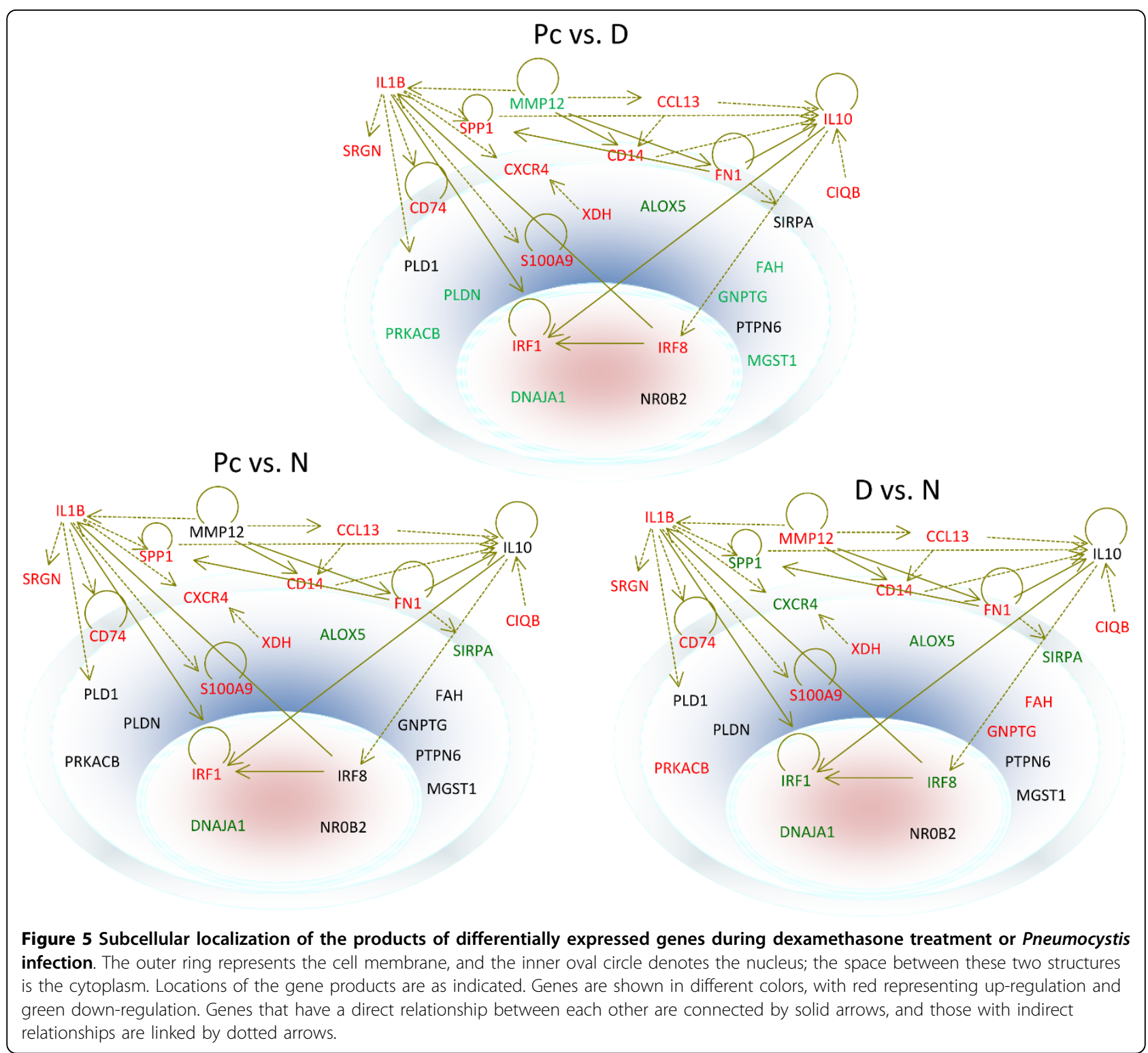

respectively). IRF-1 is a transcription factor originally found to regulate the IFN- $\beta$ gene family [40]. It also has other functions such as acting as a tumor suppressor [41], regulating the proliferation of smooth muscle cells, and activating the expression of iNOS [42]. In addition, IRF-1 induces transcription of genes such as PKR and $2 ', 5$-oligoadenylate synthetase $[43,44]$ that are involved in the defense against viral invasion. IRF-1 and IRF-8 are essential for proper functioning of mature macrophages. A defect in either gene results in the inability of the host to mount Th1-mediated immune response due to decreased production of IL-12 $[45,46]$. IRF-1 and IRF-8 together regulate numerous genes. Using microarrays, Dror et al. showed that 265 genes in activated macrophages are regulated by these two genes [47].
In addition to IRF1 and IRF8, IPA analyses revealed that IL-1 and IL-10 also play a major role in the regulation of gene expression during PCP. The expression of IL- $1 \beta$ was up-regulated 8.65 fold by dexamethasone and further up-regulated 2.26 fold by Pneumocystis infection (Table 4). IL-1 is a pro-inflammatory cytokine. Its upregulation reflects the attempt of the host to combat the infection by inflammation. Two forms of IL-1 exist: IL$1 \alpha$ and IL-1 $\beta$. IL- 1 signals mainly through the type 1 IL-1 receptor (IL-1R1), leading to NF- $\kappa$ B and c-jun activation and expression of cytokines such as TNF- $\alpha$ and interferons, as well as other inflammation-related genes. IL-10 is an anti-inflammatory cytokine. It can repress the expression of inflammatory cytokines such as TNF$\alpha$, IL- 6 , and IL- 1 by activated macrophages. The 
Table 3 Rat AM genes up-regulated by dexamethasone but down-regulated by Pneumocystis infection

\begin{tabular}{|c|c|c|}
\hline Gene & D vs. $\mathrm{N}$ & Pc vs. D \\
\hline Cdh17 & 7.15 & -1.61 \\
\hline Gsta2 & 4.77 & -2.63 \\
\hline Fxyd2 & 3.79 & -1.97 \\
\hline Hsd11b1 & 3.19 & -1.60 \\
\hline Diablo & 2.72 & -1.74 \\
\hline Mmp12 & 2.50 & -1.70 \\
\hline Ccng1 & 2.36 & -1.63 \\
\hline Btd & 2.28 & -1.85 \\
\hline Gaa & 2.27 & -1.60 \\
\hline Agt & 2.25 & -1.51 \\
\hline Hacl1 & 2.22 & -2.13 \\
\hline Prkacb & 2.03 & -1.56 \\
\hline Pcsk1 & 2.01 & -1.80 \\
\hline Tfpi & 1.98 & -1.65 \\
\hline Atp6r1d & 1.96 & -1.65 \\
\hline Hsd17b12 & 1.89 & -1.61 \\
\hline Vldlr & 1.82 & -2.17 \\
\hline Hspa9 & 1.72 & -1.72 \\
\hline Acol & 1.71 & -1.85 \\
\hline Atp6r1a & 1.69 & -1.58 \\
\hline Tceb1 & 1.62 & -1.62 \\
\hline Bloc1s2 & 1.61 & -1.63 \\
\hline Tbc1d23 & 1.60 & -3.00 \\
\hline Aifm1 & 1.57 & -1.57 \\
\hline Gpd2 & 1.57 & -1.54 \\
\hline Ufsp2 & 1.57 & -1.51 \\
\hline Gnptg & 1.56 & -1.95 \\
\hline Sqstm1 & 1.56 & -1.79 \\
\hline Hook1 & 1.55 & -1.64 \\
\hline Plod1 & 1.52 & -1.65 \\
\hline PVR & 1.51 & -1.68 \\
\hline Fah & 1.50 & -1.80 \\
\hline
\end{tabular}

Values shown are fold changes. $\mathrm{D}$ vs. $\mathrm{N}$ : expression affected by dexathamethasone (D) treatment compared to the normal control $(\mathrm{N})$; Pc vs. $\mathrm{D}$ : expression affected by Pneumocystis (Pc) infection compared to the Dex (D) control.

expression of IL-10 was not affected by dexamethasone treatment but was up-regulated 1.87 fold by Pneumocystis infection (Table 1). IL-10 has been shown to inhibit the expression of IL-1 receptor (IL-1R) gene [48] and up-regulate the expression of IL-1R antagonist [49]. Both actions would block the function of IL-1, thus decreasing production of pro-inflammatory cytokines. The fact that pro-inflammatory cytokines are produced despite IL-10 up-regulation suggests that the suppressive effects of IL-10 on IL-1 expression may be blocked during PCP.

Many (1705) genes are either up- or down-regulated in AMs during PCP. It is surprising that even though Pneumocystis is an extracellular pathogen, it is able to
Table 4 Rat AM genes up-regulated by dexamethasone and further up-regulated by Pneumocystis infection

\begin{tabular}{|c|c|c|}
\hline Gene & D vs. $\mathrm{N}$ & Pc vs. D \\
\hline S100a9 & 2.65 & 11.55 \\
\hline S100a8 & 2.50 & 6.52 \\
\hline RT1-Bb & 3.98 & 5.42 \\
\hline RT1-Db1 & 1.65 & 5.35 \\
\hline Srgn & 3.39 & 5.34 \\
\hline Ass1 & 1.62 & 5.28 \\
\hline Apoe & 2.47 & 5.23 \\
\hline $\mathrm{Cd} 74$ & 4.50 & 4.95 \\
\hline RT1-Da & 6.15 & 4.35 \\
\hline Fn1 & 10.19 & 4.20 \\
\hline $111 r_{2}$ & 3.50 & 3.14 \\
\hline Enpp3 & 2.08 & 2.88 \\
\hline Slc28a2 & 8.24 & 2.71 \\
\hline F3 & 2.87 & 2.67 \\
\hline $\mathrm{Ccl} 2$ & 9.99 & 2.65 \\
\hline Clqb & 2.04 & 2.64 \\
\hline Pon1 & 3.05 & 2.29 \\
\hline$\| 1 b$ & 8.65 & 2.26 \\
\hline Nudt4 & 3.48 & 2.15 \\
\hline $\mathrm{Cd} 14$ & 8.10 & 1.85 \\
\hline Ptafr & 1.59 & 1.84 \\
\hline $\operatorname{Arg} 1$ & 1.60 & 1.83 \\
\hline Ptgs2 & 2.01 & 1.83 \\
\hline Pstpip1 & 3.29 & 1.79 \\
\hline Pde4b & 1.88 & 1.76 \\
\hline Xdh & 5.55 & 1.74 \\
\hline Socs2 & 1.73 & 1.67 \\
\hline Bst1 & 2.34 & 1.55 \\
\hline Gda & 2.26 & 1.55 \\
\hline Ctsk & 3.68 & 1.54 \\
\hline Emb & 1.71 & 1.53 \\
\hline Ptpn1 & 2.46 & 1.50 \\
\hline
\end{tabular}

Values shown are fold changes. D vs. N: expression affected by dexathamethasone (D) treatment compared to the normal control (N); Pc vs. D: expression affected by Pneumocystis (PC) infection compared to the Dex (D) control.

affect so many genes without getting into the cells. A number of cytokines such as TNF- $\alpha$, IFN- $\gamma$, IL-1, IL-10, and IL- 8 are over produced in the lung during PCP. They may affect the expression of these genes. Pneumocystis components such as the major surface glycoprotein or $\beta$-glucans that are present in the cell wall of the organism in large quantities may have some effects. Since Pneumocystis infection results in lung damage, cellular components released may also cause differential gene expression.

Among the top 10 up-regulated genes during PCP, the chemokine (C-X-C motif) ligand 10 (Cxcl10) gene was the most highly up-regulated one with a 12-fold increase in expression. CXCL10 binds to the chemokine receptor 
Table 5 Rat AM genes down-regulated by dexamethasone but up-regulated by Pneumocystis infection

\begin{tabular}{lcc}
\hline Gene & D vs. N & Pc vs. D \\
\hline Spp1 & -1.72 & 11.78 \\
Irf1 & -1.52 & 4.45 \\
CXcr4 & -1.78 & 3.60 \\
Crp & -1.86 & 3.23 \\
II1rn & -1.83 & 2.84 \\
Irf8 & -1.61 & 2.13 \\
RT1-Aw2 & -1.97 & 2.00 \\
ler3 & -1.86 & 1.63 \\
Ccnl1 & -2.20 & 1.57 \\
\hline
\end{tabular}

Values shown are fold changes. $\mathrm{D}$ vs. N: expression affected by dexathamethasone (D) treatment compared to the normal control (N); Pc vs. D: expression affected by Pneumocystis (Pc) infection compared to the Dex (D) control.

Table 6 Rat AM genes down-regulated by dexamethasone and further down-regulated by Pneumocystis infection

\begin{tabular}{lcc}
\hline Gene & D vs. N & Pc vs. D \\
\hline Alox5 & -3.07 & -3.07 \\
Xrcc5 & -1.92 & -2.35 \\
Hmgcs1 & -1.78 & -2.18 \\
Gstm1 & -1.72 & -2.17 \\
Hspa1a & -17.44 & -2.08 \\
Ela1 & -1.62 & -2.02 \\
Ivns1abp & -1.88 & -1.95 \\
Igf1 & -1.55 & -1.81 \\
Fbp1 & -2.01 & -1.77 \\
Star & -1.85 & -1.75 \\
Dusp5 & -2.40 & -1.68 \\
Dnaja1 & -3.20 & -1.67 \\
Rgc32 & -2.87 & -1.67 \\
Pparg & -1.56 & -1.65 \\
Dnajb1 & -4.88 & -1.59 \\
Cd9 & -1.54 & -1.58 \\
Ak3 & -1.57 & -1.57 \\
St3gal2 & -1.54 & -1.56 \\
Fcgrt & -2.15 & -1.55 \\
Mtpn & -1.62 & -1.55 \\
Cdc42ep3 & -2.48 & -1.52 \\
\hline Values show & &
\end{tabular}

Values shown are fold changes. D vs. N: expression affected by dexathamethasone (D) treatment compared to the normal control (N); Pc vs. D: expression affected by Pneumocystis (Pc) infection compared to the Dex (D) control.

CXCR3 [50] and chemoattracts monocytes, macrophages, T cells, NK cells, and dendritic cells. It also promotes adhesion of $\mathrm{T}$ cells to endothelial cells [51,52]. The high degree of CXCL10 up-regulation suggests the attempts of the host to enhance AM phagocytosis. The other top up-regulated genes include Spp1, S100A9,
Table 7 Confirmation of fold changes by real-time RTPCR

\begin{tabular}{lcc}
\hline Gene & Microarray $^{\mathbf{a}}$ & Real-time RT-PCR $^{\mathbf{b}}$ \\
\hline Cat & -1.64 & -3.50 \\
Cxcl10 & 12.33 & 11.03 \\
Lcn2 & 5.36 & 15.47 \\
Nos2 & 6.35 & 14.58 \\
Sdc1 & 2.42 & 16.50 \\
Spp1 & 11.78 & 16.32 \\
\hline
\end{tabular}

${ }^{\mathrm{a}}$ Fold changes determined by microarray.

${ }^{\mathrm{b}}$ Fold changes determined by real-time RT-PCR

Rsad2, S100A8, Nos2, RT1-Bb, Lcn2, RT1-Db1, and Srgn. These genes encode the secreted phosphoprotein 1 (SPP1), calgranulin A and B complex (S100A8/ S100A9), radical S-adenosyl methionine domain containing 2 (RSAD2), inducible nitric oxide synthase (NOS2), class II MHC B $\beta$, lipocalin-2 (LCN2), class II MHC D $\beta$, and serglycin (SRGN) proteins, respectively.

As described above, the SPP1 protein plays a role in the activation of both innate and adaptive immunity. The calgranulin A and B complex (S100A8/S100A9) have been shown to be a damage-associated pattern molecule which mediates inflammatory responses and recruits inflammatory cells to sites of tissue damage [53]. It can also modulate polymerization of microtubules during migration of phagocytes and induces inflammatory responses in leucocytes and endothelial cells $[54,55]$. Their up-regulation in expression during PCP also shows the importance of phagocytosis in the defense against Pneumocystis infection. The RSAD2 protein is also known as viperin. It is an endoplasmic reticulum-associated, interferon-inducible virus inhibitory protein and has been shown to be required for optimal Th2 responses and T-cell receptor-mediated activation of NF- $\kappa \mathrm{B}$ and AP-1 [56]. The NOS2 (iNOS) protein is responsible for the production of nitric oxide which is an antimicrobial compound [57].

The lipocalin-2 protein (LCN2) is a component of granules in neutrophils from tissues that are normally exposed to microorganisms. Its level is increased during inflammation [58]. LCN2 exerts bacteriostatic effects by its ability to capture and deplete siderophores that are small iron-binding molecules synthesized by certain bacteria as a means of iron acquisition [58]. Although Pneumocystis siderophores have not been identified and the role of LCN2 in PCP is unknown, iron is known to be essential for the proliferation of Pneumocystis [59], and deferoxamine, which is an iron chelator, has been used to treat PCP in animal models [59].

Serglycin (SRGN) is a proteoglycan mainly produced by hematopoietic and endothelial cells [60]. It plays an important role in the formation of several types of 
storage granules, especially in mast cells [61]. Serglycin can bind to a variety of molecules such as histamine, chymase, tryptase, and carboxypeptidase in mast cells; elastase in neutrophile; granzyme $\mathrm{B}$ in cytotoxic $\mathrm{T}$ cells; plasminogen activator in endothelial cells; and TNF- $\alpha$ in macrophages [60]. Serglycin is important for the retention of key inflammatory mediators inside storage granules and secretory vesicles [60]. Therefore, serglycin plays a role in inflammation which is also a host defense mechanism. RT1-Bb and RT1-Db1 are class II MHC molecules [62] and are involved in antigen presentation as described above. Their up-regulation also suggests the attempts of AMs to activate adaptive immunity.

Among the ten most down-regulated genes, the expression of the lectin, galactoside-binding, soluble, 1 (Lgals1) gene is most severely reduced by Pneumocystis infection. Lgals1 encodes galectin-1 which is an endogenous lectin that can trigger lymphocyte apoptosis [63]. Its down-regulation reflects the attempts of AMs to survive. The phosphoserine aminotransferase (Psat1) gene was the second most down-regulated gene. PSAT1 is over-expressed in colon tumors [64], but its role in PCP cannot be speculated due to limited information on its function. TBC1D3 is a member of the TBC1 domain family of proteins that stimulates the intrinsic GTPase activity of RAB5A, an essential actor in early endosome trafficking [65]. Its down-regulation would affect the phagocytic function of AMs. CAR5B is the mitochondrial form of carbonic anhydrase responsible for the inter-conversion of carbon dioxide and bicarbonate to maintain acid-base balance in blood and other tissues, and to help transport carbon dioxide out of tissues [66]. The active site of most carbonic anhydrases contains a zinc ion; therefore, they are classified as metalloenzymes. Although it was one of the most severely down-regulated genes, its role in PCP is not clear.

The X-ray repair complementing defective repair in Chinese hamster cells 5 (Xrcc5) gene encodes the Ku80 protein which is a helicase involved in DNA doublestrand-break repair and chromatin remodeling [67]. Ku80 is also expressed on the surface of different types of cells and functions as an adhesion receptor for fibronectin [68] which enhances the interaction of AMs with Pneumocystis organisms [69]. Its down-regulation can be viewed as a double-edged sword as the inability of AMs to repair damaged DNA may trigger apoptosis thus decreasing their numbers, and the decrease in fibronectin receptor may decrease the phagocytic activity of AMs.

PDZ/LIM genes encode a group of proteins with diverse biological roles. In mammalian cells, there are ten genes that encode both a PDZ domain and one or several LIM domains [70]. All PDZ and LIM domain proteins can associate with and influence the actin cytoskeleton [71]. Down-regulation of any of these genes would affect the integrity of the actin cytoskeleton which plays a major role in phagocytosis. The activated leukocyte cell adhesion molecule (ALCAM) is an immunoglobulin superfamily cell adhesion molecule. It mediates both heterophilic (ALCAM-CD6) and homophilic (ALCAM-ALCAM) cell-cell interactions [72]. Its downregulation in expression would affect the movement and thus phagocytic function of AMs.

The cell death-inducing DFF45-like effector (CIDE) family proteins include CIDEA, CIDEB, and CIDEC. These proteins are important regulators of energy homeostasis and are closely linked to the development of metabolic disorders including obesity, diabetes, and liver steatosis. CIDEA may initiate apoptosis by disrupting a complex consisting of the $40-\mathrm{kDa}$ caspase-3-activated nuclease (DFF40/CAD) and its $45-\mathrm{kDa}$ inhibitor (DFF45/ICAD) [73]. Its down-regulation can be viewed as the attempt of AMs to fight for survival by decreasing CIDEA-mediated apoptosis.

\section{Conclusions}

Our data provide the first comprehensive description of the response of AMs to Pneumocystis infection using microarray and revealed a wide variety of genes and cellular functions that are affected by dexamethasone or Pneumocystis infection. Dexamethasone will continue to be used for immunosuppression if the rat PCP model is to be used for study of Pneumocystis infection. Knowing what dexamethasone will do to the cells will give investigators a better insight in studying the effect of Pneumocystis infection on gene expression and function of AMs. This study also revealed many defects of AMs that may occur during Pneumocystis infection, as many genes whose expressions are affected by the infection. Investigation of these genes will allow us to better understand the mechanisms of pathogenesis of PCP.

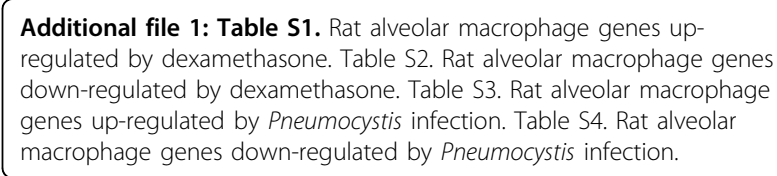

\section{Abbreviations}

Aco1: aconitase 1; Agt: angiotensinogen; Aifm1: apoptosis-inducing factor, mitochondrion-associated 1; Ak3: adenylate kinase 3; Alcam: activated leukocyte cell adhesion molecule; Alox5: arachidonate 5-lipoxygenase; Apoe: apolipoprotein E; Arg1: arginase 1, liver; Ass1: argininosuccinate synthetase 1; Atf3: activating transcription factor 3; Atp6v1a: ATPase, $\mathrm{H}$ transporting, lysosomal V1 subunit A; Atp6v1d: ATPase, $\mathrm{H}+$ transporting, lysosomal V1 subunit D; Azin1: antizyme inhibitor 1; Bloc1s2: biogenesis of lysosomerelated organelles complex-1, subunit 2; Bnip3l: BCL2/adenovirus E1B interacting protein 3-like; Bst1: bone marrow stromal cell antigen 1; Btd: biotinidase; Calm 1: calmodulin 1; C3: complement component 3; C1 qb: complement component 1, q subcomponent, beta polypeptide; Car5b: 
carbonic anhydrase 5b, mitochondrial; Cat: atalase; Cxcl13: chemokine (C-X-C motif) ligand 13; CCl2: chemokine ( $\mathrm{C}-\mathrm{C}$ motif) ligand 2; C $\mathrm{Cl}$ : chemokine (C-C motif) ligand 5; Ccng1: cyclin G1; Ccnl1: cyclin L1; Ccr1: chemokine (C-C motif) receptor 1; Ccr5: chemokine (C-C motif) receptor 5; Cd14: CD14 molecule; Cd55: CD55 antigen; Cd74: CD74 antigen (invariant polypeptide of major histocompatibility complex, class I; Cd81: CD 81 antigen; Cd9: CD9 antigen; Cdc42ep3: CDC42 effector protein (Rho GTPase binding) 3; Cdh17: cadherin 17; Cidea: cell death-inducing DNA fragmentation factor, alpha subunit-like effector A; Clu: lusterin; Crp: C-reactive protein, pentraxin-related; Ctsk: cathepsin $\mathrm{K}$; Cxcl1: chemokine (C-X-C motif) ligand 1; Cxcl10: chemokine (C-X-C motif) ligand 10; CXCr4: chemokine (C-X-C motif) receptor 4; Diablo: diablo homolog; Dnaja1: DnaJ (Hsp40) homolog, subfamily A, member 1; Dnajb1: DnaJ (Hsp40) homolog, subfamily B, member 1; Dusp5: dual specificity phosphatase 5; Ela1: elastase 1; Emb: embigin; Enpp3: ectonucleotide pyrophosphatase/phosphodiesterase 3; F3: coagulation factor III; Fah: fumarylacetoacetate hydrolase; Fbp1: fructose-1,6- biphosphatase 1; Fcgrt: Fc receptor, IgG, alpha chain transporter; Fn1: fibronectin 1; Fos: FBJ osteosarcoma oncogene; Fxyd2: FXYD domain-containing ion transport regulator 2; Gaa: glucosidase, alpha, acid; Gbp2: guanylate nucleotide binding protein 2; Gda: guanine deaminase; Gnptg: N-acetylglucosamine-1phosphotransferase, gamma subunit; Gpd2: glycerol-3-phosphate dehydrogenase 2, mitochondrial; Gsta2: glutathione-S-transferase, alpha type 2; Gstm1: glutathione S-transferase, mu 1; Hacl1: 2-hydroxyacyl-CoA lyase 1; Hdac2: histone deacetylase 2; Hip1: huntingtin interacting protein 1; Hmgcs1: 3-hydroxy-3-methylglutaryl-coenzyme A synthase 1; Hook1: hook homolog 1; Hsd11b1: hydroxysteroid 11-beta dehydrogenase 1; Hsd17b12: hydroxysteroid 17-beta dehydrogenase 12; Hspala: heat shock 70kD protein 1A; Hspa1b: heat shock 70 kD protein 1B; Hspa9: Heat shock protein 9; Hspb1: heat shock protein 1; Hsph1: heat shock $105 \mathrm{kDa} / 110 \mathrm{kDa}$ protein 1; ler3: immediate early response 3; Igf1: insulin-like growth factor 1; II10: interleukin 10; $\| 1$ b: interleukin 1 beta; $\| 1$ r2: interleukin 1 receptor, type $\|_{\text {; }}$ ॥1 rn: interleukin 1 receptor antagonist; IL8rb: interleukin 8 receptor, beta; Irf: interferon regulatory factor 1 ; Irf7: interferon regulatory factor 7 ; Irf8: interferon regulatory factor 8; Ivns1abp: influenza virus NS1A binding protein; Lcn2: lipocalin 2; Lgals1: ectin, galactose binding, soluble 1; Mgst1: microsomal glutathione S-transferase 1; Mmp12: matrix metallopeptidase 12; Mmp14: matrix metallopeptidase 14; Mmp7: matrix metallopeptidase 7; Mmp8: matrix metallopeptidase 8; Mtpn: myotrophin; Mx1: myxovirus resistance 1; Mx2: myxovirus resistance 2; Nos2: nitric oxide synthase 2, inducible, macrophage; Nr1h3: nuclear receptor subfamily 1, group $\mathrm{H}$, member 3; Nudt4: nucleoside diphosphate linked moiety $X$ type motif 4; Oas1a: 2'-5' oligoadenylate synthetase 1A; Odc1: ornithine decarboxylase 1; Pcsk1: proprotein convertase subtilisin/kexin type 1; Pde4b: phosphodiesterase 4B, CAMP specific; Pdlim1: PDZ and LIM domain 1; Pkib: protein kinase inhibitor beta; PId1: phospholipase D1; Plod1: procollagenlysine, 2-oxoglutarate 5-dioxygenase 1; Pon1: paraoxonase 1; Pparg: peroxisome proliferator activated receptor gamma; Ppp6c: protein phosphatase 6, catalytic subunit; Prf1: perforin 1; Prkacb: protein kinase, cAMP dependent, catalytic, beta; Prkcb1: protein kinase C, beta; Psat1: phosphoserine aminotransferase 1; Psmb9: proteosome subunit, beta type 9; Pstpip1: proline-serine-threonine phosphatase-interacting protein 1; Ptafr: platelet-activating factor receptor; Ptgs2: prostaglandin-endoperoxide synthase 2; Ptpn1: protein tyrosine phosphatase, non-receptor type 1; Ptprc: protein tyrosine phosphatase, receptor type C; Pvr: poliovirus receptor; Rgc32: response gene to complement 32; Rps8: ribosomal protein subunit 8; Rsad2: radical S-adenosyl methionine domain containing 2; RT1-Aw2: RT1 class Ib, locus Aw2; RT1-Bb: class II histocompatibility antigen, B-1 beta chain; RT1-Da: RT1 class II, locus Da; RT1-Db1: RT1 class II, locus Db1; S100a8: S100 calcium binding protein A8 (calgranulin A); S100a9: S100 calcium binding protein A9 (calgranulin B); Sdc4: syndecan 4; Sell: selectin, lymphocyte; SIc28a2: solute carrier family 28, member 2; Smo: spermine oxidase; Socs2: suppressor of cytokine signaling 2; Socs3: suppressor of cytokine signaling 3; Sod2: superoxide dismutase 2, mitochondrial; Spp1: secreted phosphoprotein 1; Sqstm1: sequestosome 1; Srgn: serglycin; St3gal2: ST3 beta-galactoside alpha-2,3-sialyltransferase 2; Star: steroidogenic acute regulatory protein; Tac1: tachykinin 1; Tap1: transporter 1, ATP-binding cassette; Tap2: transporter 2, ATP-binding cassette; Tbc1d23: TBC1 domain family, member 23; Tceb1: transcription elongation factor B, polypeptide 1; Tfpi: tissue factor pathway inhibitor; Trf: transferrin; Ufsp2: UFM1-specific peptidase 2; Vldlr: very low density lipoprotein receptor; Xdh: xanthine dehydrogenase; Xrcc5: X-ray repair complementing defective repair in Chinese hamster cells 5.

\section{Acknowledgements}

This study was supported by grants from the National Institutes of Health (RO1 HL65170 and RO1 Al062259). We thank the Center for Medical Genomics at Indiana University School of Medicine for assistance in Affymetrix GeneChip analysis.

\section{Author details}

'Department of Obstetrics and Gynecology, Chang Gung Memorial Hospital - Kaohsiung Medical Center, Chang Gung University College of Medicine, Kaohsiung, Taiwan. ${ }^{2}$ Graduate Institute of Clinical Medical Sciences, Chang Gung University College of Medicine, Kaohsiung, Taiwan. ${ }^{3}$ Division of Biostatistics, Department of Medicine, Indiana University School of Medicine, Indianapolis, IN 46202, USA. ${ }^{4}$ Center for Computational Biology and Bioinformatics, Indiana University School of Medicine, Indianapolis, IN 46202, USA. ${ }^{5}$ Center for Medical Genomics, Indiana University School of Medicine, Indianapolis, IN 46202, USA. ${ }^{6}$ Department of Biochemistry and Molecular Biology, Indiana University School of Medicine, Indianapolis, IN 46202, USA. ${ }^{7}$ Department of Pathology and Laboratory Medicine, Indiana University School of Medicine, Indianapolis, IN 46202, USA. ${ }^{8}$ Department of Surgery, Teda Hospital, Tianjin, China. ${ }^{9}$ Graduate Institute of Clinical Medical Science and Department of Laboratory Medicine, China Medical University, Taichung, Taiwan.

\section{Authors' contributions}

$B H C, Y L$, and $X X$ analyzed the microarray results. $D L, C P L, M E L$, and PJD performed the microarray experiments. $\mathrm{CHL}$ designed the experiments and wrote the manuscript. All authors read and approved the final manuscript.

\section{Received: 11 November 2009 Accepted: 8 April 2010} Published: 8 April 2010

\section{References}

1. Sepkowitz KA: Opportunistic infections in patients with and patients without Acquired Immunodeficiency Syndrome. Clin Infect Dis 2002, 34(8):1098-1107.

2. Tellez I, Barragán M, Franco-Paredes C, Petraro P, Nelson K, Del Rio C: Pneumocystis jiroveci pneumonia in patients with AIDS in the inner city: a persistent and deadly opportunistic infection. Am J Med Sci 2008, 335(3):192-197.

3. Mocroft A, Sabin CA, Youle M, Madge S, Tyrer M, Devereux H, Deayton J, Dykhoff A, Lipman MC, Phillips AN, et al: Changes in AIDS-defining illnesses in a London Clinic, 1987-1998. J Acquir Immune Defic Syndr 1999, 21(5):401-407.

4. Matsumoto Y, Matsuda S, Tegoshi T: Yeast glucan in the cyst wall of Pneumocystis carinii. J Protozool 1989, 36(1):21S-22S.

5. Walker AN, Garner RE, Horst MN: Immunocytochemical detection of chitin in Pneumocystis carinii. Infect Immun 1990, 58(2):412-415.

6. Edman JC, Kovacs JA, Masur H, Santi DV, Elwood HJ, Sogin ML: Ribosomal RNA sequence shows Pneumocystis carinii to be a member of the fungi. Nature 1988, 334(6182):519-522.

7. Stringer SL, Stringer JR, Blase MA, Walzer PD, Cushion MT: Pneumocystis carinii : sequence from ribosomal RNA implies a close relationship with fungi. Exp Parasitol 1989, 68(4):450-461.

8. Watanabe J, Hori H, Tanabe K, Nakamura Y: Phylogenetic association of Pneumocystis carinii with the 'Rhizopoda/Myxomycota/Zygomycota group' indicated by comparison of $5 \mathrm{~S}$ ribosomal RNA sequences. Mol Biochem Parasitol 1989, 32(2-3):163-167.

9. Pixley FJ, Wakefield AE, Banerji S, Hopkin JM: Mitochondrial gene sequences show fungal homology for Pneumocystis carinii . Mol Microbiol 1991, 5(6):1347-1351.

10. Gigliotti F, Harmsen AG, Haidaris CG, Haidaris PJ: Pneumocystis carinii is not universally transmissible between mammalian species. Infect Immun 1993, 61(7):2886-2890.

11. Stringer JR, Beard CB, Miller RF, Wakefield AE: A new name (Pneumocystis jiroveci) for Pneumocystis from humans. Emerg Infect Dis 2002, 8(9):891-896. 
12. Chen W, Mills JW, Harmsen AG: Development and resolution of Pneumocystis carinii pneumonia in severe combined immunodeficient mice: a morphological study of host inflammatory responses. Int J Exp Pathol 1992, 73(6):709-720.

13. Lanken PN, Minda M, Pietra GG, Fishman AP: Alveolar response to experimental Pneumocystis carinii pneumonia in the rat. Am J Pathol 1980, 99(3):561-588.

14. Fleury J, Escudier E, Pocholle MJ, Carre C, Bernaudin JF: Cell population obtained by bronchoalveolar lavage in Pneumocystis carinii pneumonitis. Acta Cytol 1985, 29(5):721-726.

15. Fleury-Feith J, Van Nhieu JT, Picard C, Escudier E, Bernaudin JF: Bronchoalveolar lavage eosinophilia associated with Pneumocystis carinii pneumonitis in AIDS patients. Comparative study with non-AIDS patients. Chest 1989, 95(6):1198-1201.

16. Young JA, Stone JW, McGonigle RJ, Adu D, Michael J: Diagnosing Pneumocystis carinii pneumonia by cytological examination of bronchoalveolar lavage fluid: report of 15 cases. J Clin Pathol 1986, 39(9):945-949.

17. Lasbury ME, Durant PJ, Ray CA, Tschang D, Schwendener R, Lee CH: Suppression of alveolar macrophage apoptosis prolongs survival of rats and mice with Pneumocystis pneumonia. J Immunol 2006, 176(11):6443-6453.

18. Lasbury ME, Merali S, Durant PJ, Tschang D, Ray CA, Lee CH: Polyaminemediated apoptosis of alveolar macrophages during Pneumocystis pneumonia. J Biol Chem 2007, 282(15):11009-11020.

19. Liao CP, Lasbury ME, Wang SH, Zhang C, Durant PJ, Murakami Y, Matsufuji S, Lee CH: Pneumocystis mediates overexpression of antizyme inhibitor resulting in increased polyamine levels and apoptosis in alveolar macrophages. J Biol Chem 2009, 284(12):8174-8184.

20. Koziel H, Eichbaum Q, Kruskal BA, Pinkston P, Rogers RA, Armstrong MY, Richards FF, Rose RM, Ezekowitz RAB: Reduced binding and phagocytosis of Pneumocystis carinii by alveolar macrophages from persons infected with HIV-1 correlates with mannose receptor downregulation. J Clin Invest 1998, 102(7):1332-1344.

21. Bartlett MS, Fishman JA, Queener SF, Durkin MM, Jay MA, Smith JW: New rat model of Pneumocystis carinii infection. J Clin Microbiol 1988 26(6):1100-1102.

22. Lasbury ME, Tang $X$, Durant PJ, Lee $\mathrm{CH}$ : Effect of transcription factor GATA-2 on phagocytic activity of alveolar macrophages from Pneumocystis carinii -infected hosts. Infect Immun 2003, 71(9):4943-4952.

23. Lasbury ME, Durant PJ, Bartlett MS, Smith JW, Lee CH: Correlation of organism burden and alveolar macrophage counts during infection with Pneumocystis carinii and recovery. Clin Diagn Lab Immunol 2003, 10(2):293-302.

24. Lauren PD: Algorithm to model gene expression on Affymetrix chips without the use of MM cells. IEEE Trans Nanobioscience 2003, 2(3):163-170.

25. Zhang C, Wang SH, Lasbury ME, Tschang D, Liao CP, Durant PJ, Lee CH: Toll-like receptor 2 mediates alveolar macrophage response to Pneumocystis murina . Infect Immun 2006, 74(3):1857-1864.

26. Kottom TJ, Limper $\mathrm{AH}$ : Microarray analysis of lung epithelial responses to Pneumocystis carinii . J Eukaryot Microbiol 2003, 50(Suppl):629.

27. Hernandez-Novoa B, Bishop L, Logun C, Munson PJ, Elnekave E, Rangel ZG, Barb J, Danner RL, Kovacs JA: Immune responses to Pneumocystis murina are robust in healthy mice but largely absent in CD40 ligand-deficient mice. J Leukoc Biol 2008, 84(2):420-430.

28. Kovacs EM, Goodwin M, Ali RG, Paterson AD, Yap AS: Cadherin-directed actin assembly: E-cadherin physically associates with the Arp2/3 complex to direct actin assembly in nascent adhesive contacts. Curr Biol 2002, 12(5):379-382.

29. Pokutta S, Drees F, Takai Y, Nelson WJ, Weis WI: Biochemical and structural definition of the I-afadin- and actin-binding sites of alpha-catenin. $J$ Biol Chem 2002, 277(21):18868-18874.

30. Douglas KT: Mechanism of action of glutathione-dependent enzymes. Adv Enzymol Relat Areas Mol Biol 1987, 59:103-167.

31. Leaver MJ, George SG: A piscine glutathione S-transferase which efficiently conjugates the end-products of lipid peroxidation. Marine Environmental Research 1998, 46(1-5):71-74.

32. Yang Y, Parsons KK, Chi L, Malakauskas SM, Le TH: Glutathione Stransferase-micro1 regulates vascular smooth muscle cell proliferation, migration, and oxidative stress. Hypertension 2009, 54(6):1360-1368.
33. Sawyer RT, Dobis DR, Goldstein M, Velsor L, Maier LA, Fontenot AP, Silveira L, Newman LS, Day BJ: Beryllium-stimulated reactive oxygen species and macrophage apoptosis. Free Radic Biol Med 2005, 38(7):928-937.

34. Lund SA, Giachelli CM, Scatena M: The role of osteopontin in inflammatory processes. J Cell Commun Signal 2009, 3(3-4):311-322.

35. Wang KX, Denhardt DT: Osteopontin: role in immune regulation and stress responses. Cytokine Growth Factor Rev 2008, 19(5-6):333-345.

36. Laffón A, Garcia-Vicuña R, Humbria A, Postigo AA, Corbí AL, de Landázuri MO, Sánchez-Madrid F: Upregulated expression and function of VLA-4 fibronectin receptors on human activated T cells in rheumatoid arthritis. J Clin Invest 1991, 88(2):546-552.

37. Seiffge D: Protective effects of monoclonal antibody to VLA-4 on leukocyte adhesion and course of disease in adjuvant arthritis in rats. $J$ Rheumatol 1996, 23(12):2086-2091.

38. Woodruff $P G$, Koth LL, Yang YH, Rodriguez MW, Favoreto S, Dolganov GM, Paquet $A C$, Erle DJ: A distinctive alveolar macrophage activation state induced by cigarette smoking. Am J Respir Crit Care Med 2005, 172(11):1383-1392.

39. Mangum J, Bermudez E, Sar M, Everitt J: Osteopontin expression in particle-induced lung disease. Exp Lung Res 2004, 30(7):585-598.

40. Miyamoto M, Fujita T, Kimura Y, Maruyama M, Harada H, Sudo Y, Miyata T, Taniguchi T: Regulated expression of a gene encoding a nuclear factor, IRF-1, that specifically binds to IFN-beta gene regulatory elements. Cell 1988, 54(6):903-913.

41. Vaughan PS, van Wijnen AJ, Stein JL, Stein GS: Interferon regulatory factors: growth control and histone gene regulation-it's not just interferon anymore. J Mol Med 1997, 75(5):348-359.

42. Spink J, Evans T: Binding of the transcription factor interferon regulatory factor- 1 to the inducible nitric-oxide synthase promoter. $J$ Biol Chem 1997, 272(39):24417-24425.

43. Kirchhoff S, Koromilas AE, Schaper F, Grashoff M, Sonenberg N, Hauser H: IRF-1 induced cell growth inhibition and interferon induction requires the activity of the protein kinase PKR. Oncogene 1995, 11(3):439-445.

44. Benech $P$, Vigneron $M$, Peretz D, Revel M, Chebath J: Interferon-responsive regulatory elements in the promoter of the human 2 ', $5^{\prime}$-oligo(A) synthetase gene. Mol Cell Biol 1987, 7(12):4498-4504.

45. Wang IM, Contursi C, Masumi A, Ma X, Trinchieri G, Ozato K: An IFNgamma-inducible transcription factor, IFN consensus sequence binding protein (ICSBP), stimulates IL-12 p40 expression in macrophages. J Immunol 2000, 165(1):271-279.

46. Taki S, Sato T, Ogasawara K, Fukuda T, Sato M, Hida S, Suzuki G, Mitsuyama M, Shin EH, Kojima S, et al: Multistage regulation of Th1-type immune responses by the transcription factor IRF-1. Immunity 1997, 6(6):673-679.

47. Dror N, Alter-Koltunoff M, Azriel A, Amariglio N, Jacob-Hirsch J, Zeligson S, Morgenstern A, Tamura T, Hauser H, Rechavi G, et al: Identification of IRF-8 and IRF-1 target genes in activated macrophages. Mol Immunol 2007, 44(4):338-346.

48. Dickensheets HL, Donnelly RP: IFN-gamma and IL-10 inhibit induction of IL-1 receptor type I and type II gene expression by IL-4 and IL-13 in human monocytes. J Immunol 1997, 159(12):6226-6233.

49. Berlato C, Cassatella MA, Kinjyo I, Gatto L, Yoshimura A, Bazzoni F: Involvement of suppressor of cytokine signaling-3 as a mediator of the inhibitory effects of IL-10 on lipopolysaccharide-induced macrophage activation. J Immunol 2002, 168(12):6404-6411.

50. Booth V, Keizer DW, Kamphuis MB, Clark-Lewis I, Sykes BD: The CXCR3 binding chemokine IP-10/CXCL10: structure and receptor interactions. Biochemistry 2002, 41(33):10418-10425.

51. Dufour JH, Dziejman M, Liu MT, Leung JH, Lane TE, Luster AD: IFN-gammainducible protein 10 (IP-10; CXCL10)-deficient mice reveal a role for IP10 in effector T cell generation and trafficking. J Immunol 2002, 168(7):3195-3204.

52. Angiolillo AL, Sgadari C, Taub DD, Liao F, Farber JM, Maheshwari S, Kleinman HK, Reaman GH, Tosato G: Human interferon-inducible protein 10 is a potent inhibitor of angiogenesis in vivo. J Exp Med 1995, 182(1):155-162.

53. Foell D, Wittkowski H, Vogl T, Roth J: S100 proteins expressed in phagocytes: a novel group of damage-associated molecular pattern molecules. J Leukoc Biol 2007, 81(1):28-37. 
54. Vogl T, Ludwig S, Goebeler M, Strey A, Thorey IS, Reichelt R, Foell D, Gerke V, Manitz MP, Nacken W, et al: MRP8 and MRP14 control microtubule reorganization during transendothelial migration of phagocytes. Blood 2004, 104(13):4260-4268.

55. Ryckman C, Vandal K, Rouleau P, Talbot M, Tessier PA: Proinflammatory activities of S100: proteins S100A8, S100A9, and S100A8/A9 induce neutrophil chemotaxis and adhesion. J Immunol 2003, 170(6):3233-3242.

56. Qiu LQ, Cresswell $P$, Chin KC: Viperin is required for optimal Th2 responses and T-cell receptor-mediated activation of NF-kappaB and AP1. Blood 2009, 113(15):3520-3529.

57. Tripathi P: Nitric oxide and immune response. Indian J Biochem Biophys 2007, 44(5):310-319.

58. Schmidt-Ott KM, Mori K, Li JY, Kalandadze A, Cohen DJ, Devarajan P, Barasch J: Dual action of neutrophil gelatinase-associated lipocalin. J Am Soc Nephrol 2007, 18(2):407-413.

59. Merali S, Chin K, Del Angel L, Grady RW, Armstrong M, Clarkson AB Jr: Clinically achievable plasma deferoxamine concentrations are therapeutic in a rat model of Pneumocystis carinii pneumonia. Antimicrob Agents Chemother 1995, 39(9):2023-2026.

60. Kolset SO, Tveit H: Serglycin-structure and biology. Cell Mol Life Sci 2008, 65(7-8):1073-1085.

61. Pejler $G$, Abrink $M$, Wernersson $S$ : Serglycin proteoglycan: regulating the storage and activities of hematopoietic proteases. Biofactors 2009, 35(1):61-68.

62. Chao NJ, Timmerman L, McDevitt HO, Jacob CO: Molecular characterization of MHC class II antigens (beta 1 domain) in the BB diabetes-prone and -resistant rat. Immunogenetics 1989, 29(4):231-234.

63. Pang M, He J, Johnson P, Baum LG: CD45-mediated fodrin cleavage during galectin-1 $\mathrm{T}$ cell death promotes phagocytic clearance of dying cells. J Immunol 2009, 182(11):7001-7008.

64. Vié N, Copois V, Bascoul-Mollevi C, Denis V, Bec N, Robert B, Fraslon C, Conseiller E, Molina F, Larroque C, et al: Overexpression of phosphoserine aminotransferase PSAT1 stimulates cell growth and increases chemoresistance of colon cancer cells. Mol Cancer 2008, 7:14.

65. Hodzic D, Kong C, Wainszelbaum MJ, Charron AJ, Su X, Stahl PD: TBC1D3, a hominoid oncoprotein, is encoded by a cluster of paralogues located on chromosome 17q12. Genomics 2006, 88(6):731-736.

66. Lindskog S: Structure and mechanism of carbonic anhydrase. Pharmacol Ther 1997, 74(1):1-20

67. Park SJ, Ciccone SL, Freie B, Kurimasa A, Chen DJ, Li GC, Clapp DW, Lee SH: A positive role for the Ku complex in DNA replication following strand break damage in mammals. J Biol Chem 2004, 279(7):6046-6055.

68. Monferran S, Muller C, Mourey L, Frit P, Salles B: The Membrane-associated form of the DNA repair protein $\mathrm{Ku}$ is involved in cell adhesion to fibronectin. J Mol Biol 2004, 337(3):503-511.

69. Neese LW, Standing JE, Olson EJ, Castro M, Limper AH: Vitronectin, fibronectin, and gp120 antibody enhance macrophage release of TNFalpha in response to Pneumocystis carinii . J Immunol 1994, 152(9):4549-4556.

70. te Velthuis AJ, Bagowski CP: PDZ and LIM domain-encoding genes: molecular interactions and their role in development. ScientificWorld Journal 2007, 7:1470-1492.

71. Vallenius T, Scharm B, Vesikansa A, Luukko K, Schäfer R, Mäkelä TP: The PDZ-LIM protein RIL modulates actin stress fiber turnover and enhances the association of alpha-actinin with F-actin. Exp Cell Res 2004, 293(1):117-128.

72. Swart GW: Activated leukocyte cell adhesion molecule (CD166/ALCAM): developmental and mechanistic aspects of cell clustering and cell migration. Eur I Cell Biol 2002, 81(6):313-321.

73. Valousková E, Smolková K, Santorová J, Jezek P, Modriansky M: Redistribution of cell death-inducing DNA fragmentation factor-like effector-a (CIDEa) from mitochondria to nucleus is associated with apoptosis in HeLa cells. Gen Physiol Biophys 2008, 27(2):92-100.

doi:10.1186/1471-2180-10-103

Cite this article as: Cheng et al: Microarray studies on effects of Pneumocystis carinii infection on global gene expression in alveolar macrophages. BMC Microbiology 2010 10:103.

\section{Submit your next manuscript to BioMed Central and take full advantage of:}

- Convenient online submission

- Thorough peer review

- No space constraints or color figure charges

- Immediate publication on acceptance

- Inclusion in PubMed, CAS, Scopus and Google Scholar

- Research which is freely available for redistribution 